\title{
Alienation and Digital Labour-A Depth-Hermeneutic Inquiry into Online Commodification and the Unconscious
}

\author{
Steffen Krüger ${ }^{*}$ and Jacob Johanssen ${ }^{\dagger}$ \\ "University of Oslo, Norway, steffen.krueger@media.uio.no \\ ${ }^{\dagger}$ University of East London, England, jacob@cyborgsubjects.org
}

\begin{abstract}
At the core of this paper is a psychosocial inquiry into the Marxist concept of alienation and its applications to the field of digital labour. Following a brief review of theoretical works on alienation, it looks into its recent conceptualisations and applications to the study of online social networking sites. Subsequently, the authors offer suggestions on how to extend and render more complex these recent approaches through in-depth analyses of Facebook posts that exemplify how alienation is experienced, articulated, and expressed online. Supporting this perspective, the article draws on Rahel Jaeggi's (2005) reassessment of alienation, as well as the depth-hermeneutic method of "scenic understanding" developed by Alfred Lorenzer (e.g. 1970; 1986).
\end{abstract}

Keywords: Alienation, Psychoanalysis, Alfred Lorenzer, Digital Labour, Depth-Hermeneutics, Psychosocial

\section{Introduction}

In his 2011 article "Surveillance and Alienation in the Online Economy", Mark Andrejevic makes the following observation apropos alienation and the specific form that the concept takes on in online social networking practices.

\begin{abstract}
Each form of intentional user-generated content-a blog post, a Facebook update, a Tweet, is redoubled in the form of 'cybernetic commodities' (Mosco 1989). [...] [W]hile they are created by users, they are not controlled by users, who have little choice over how and when this data is generated and little say in how it is used. In this sense we might describe the generation and use of this data as the alienated or estranged dimension of their activity. To the extent that this information can be used to predict and influence user behaviour it is an activity that returns to users in an unrecognizable form as a means of fulfilling the imperatives of others (Andrejevic 2011, 286, our emphasis).
\end{abstract}

This is an extremely fertile point of departure for thinking about the uses of the concept of alienation in the online sphere. Since our aim in this paper is to contribute to the discussion of alienation within the study of digital labour from a psychoanalytically oriented perspective, Andrejevic's observations here are highly suggestive. He creates a scenario in which alienation arises not simply on the basis of the users' symbolic production on a given corporate platform; rather, he presents the feeding back of the produced and double-used data as a decisive part in the dynamics of alienation. In so doing, he opens up for a complex and sophisticated conception of the relation between a social networking site (SNS) and its users, as well as the potential place of alienation within it.

Indeed, the nuance which Andrejevic adds to his text, namely that it is not simply a product that "returns to users" in disguise, but an activity (Andrejevic 2011, 286) moves his observation yet closer to psychodynamic thinking, where we suspect a strong connection between intra and inter-psychic processes. Thus, a psychoanalytically informed perspective is geared to seek out why-as well as how-we do not recognise that which returns to us users, as well as how we fare under-and suffer from-a relationship in the making of which we do not recognise our own hand. It is questions such as these that we want to put forth in this paper. 
We will approach these questions by presenting in-depth readings of an exemplary choice of users' posts to Facebook's Site Governance Page. For these in-depth readings we will rely on the "depth-hermeneutic approach to cultural analysis", which was developed by the sociologist and psychoanalyst Alfred Lorenzer (1922-2002) throughout the 1970s and 1980s (e.g. Lorenzer and Orban 1987/88). What depth-hermeneutics offers is a theoretical and methodological frame for interpreting concrete articulations of and within a culture from both a psychoanalytic and culture-analytic angle. Depth hermeneutics places the vantage point of our inquiry first and foremost on the subjective, i.e. users' symbolic production itself. The reading of this production as symptomatic-as subjective articulations of the objective societal conditions-will allow us to lay open the specific form of online alienation in the relations between the subjective and its socio-cultural context. How does alienation make itself felt in the production and, ultimately, in the products at the heart of the exploitative structure of online social networks that Andrejevic describes above?

In order to set the stage for our inquiry we will first give a brief overview of the history of the concept of alienation. We will then turn to the contemporary debate on digital labour and the place of alienation therein. The main part of this article will consist of our exemplary analyses of online alienation.

\section{A Brief History of Alienation}

Alienation holds a particularly central place in Marxist theory; after all, it is the category that decisively mediates between a worker's living conditions and the relations of production, between the subject and its objects, or even between the subjective and the objective in the social per se.

It is this in-between position that Marx [1844] (1988) granted alienation that made the concept so extremely popular in the tradition of critical thinking about culture and society. Jon Elster (1986) deems alienation to be "the most important concept" of Marx's normative theory (Elster 1986, 41). "The efficacy of capitalist exploitation," he writes, "rests on its ability to perpetuate the conditions under which it appears as morally legitimate" (ibid, 56). Marcello Musto (2010), in turn, traces the concept's career as the main pillar of the critique of capitalism's efficacy throughout long stretches of the intellectual history of the $20^{\text {th }}$ century. After the publication of Marx's Economic and Philosophic Manuscripts from 1844 in 1932 several Frankfurt School authors, such as Adorno and Horkheimer (1972), Herbert Marcuse (1966), Erich Fromm (1961; 1965), produced Freudo-Marxist readings of alienation (Musto 2010, 83-85). French existentialists, in turn, rendered the concept "much more generic than in Marx's thought", identifying it "with a diffuse discontent of man in society" (ibid, 86-87), and the 1960s, then, literally became "the age of alienation tout court" in which,

authors from various political backgrounds and academic disciplines identified its causes as commodification, overspecialization, anomie, bureaucratization, conformism, consumerism, loss of a sense of self amid new technologies, even personal isolation, apathy, social or ethnic marginalization, and environmental pollution (Musto 2010, 90).

In view of this "craze" it might be understandable why, at the beginning of the $21^{\text {st }}$ century, Rahel Jaeggi (2005) can observe that the term nearly disappeared from all sociophilosophical literature.

Too inflationary was the use of the term alienation in its boom phase, too old-fashioned and outdated its philosophical foundations in the age of the 'postmodern', too questionable its political consequences in the age of "political liberalism"-and probably also too pointless the concern of the critique of alienation under the sway of victorious capitalism (Jaeggi 2005, 11).

However, it was specifically developments in the online sphere, such as the increasingly monopolistic corporate structures on the World Wide Web and the orientation towards the generation of exchange value, that have brought the concept of alienation, together with the full 
set of Marxist terminology, back onto the social scientific agenda. Especially media and communication scholars (Comor 2010; Andrejevic 2011, 2014; Fuchs 2012a; Fisher 2012; Giritli Nygren and Gidlund 2012; Fuchs and Sevignani 2013; Sevignani 2013), have successfully resuscitated Marxist terminology-and specifically alienation-to examine social networking sites more closely.

\title{
3. Alienation Defined
}

There are two texts by Karl Marx that have proven canonical for the current critical understanding of alienation in digital labour. We will start with the chronologically later passage, which can be found in Marx's Grundrisse [1857-61] (1973). Here, Marx writes apropos the "real alien relation [Fremdheit] of the worker to his product":

\begin{abstract}
The material on which it [i.e. living labour capacity; S.K. and J.J.] works is alien material; the instrument is likewise an alien instrument [...]. Indeed, living labour itself appears as alien vis-à-vis living labour capacity, whose labour it is, whose own life's expression it is, for it has been surrendered to capital in exchange for objectified labour, for the product of labour itself (Marx 1857-61 [1973], 394, italics in original).
\end{abstract}

Four dimensions of alienation can be identified in this passage, specifically: (1) alienation from the material of one's labour, (2), alienation from the instruments, (3) alienation from the product(s), and (4) alienation from oneself (i.e. living labour as "alien vis-à-vis living labour capacity"). It is along these lines that Fuchs and Sevignani (2013) detect and list the various variables of alienation on online SNSs. Before turning to their article, however, we would like to introduce the chronologically earlier passage on alienation by Marx, which can be found in the Economic and Philosophic Manuscripts [1844] (1956/2009). Already here Marx identified four dimensions of alienation; yet, his formulations in this text are more straightforwardly directed towards its relational aspects-a difference which ultimately produces different categories as well. Thus, one can sum up Marx's early observations as follows: The worker is alienated (1) in the "relation [...] to the product of labour" and (2) in the "relation [...] to the act of production in the labour process" (Marx 1844 [1956/2009], 30-31); these two alienated relations have a further alienating effect, specifically that of "estranging" the worker (3) from her/himself ${ }^{1}$ as well as (4) from others:

What applies to a man's relation to his work, to the product of his labor and to himself, also holds to a man's relation to the other man, and to the other man's labor and object of labor. [...] The estrangement of man, and in fact every relationship in which man [stands] to himself, is realized and expressed only in the relationship in which a man stands to other men (ibid, 32).

As with Andrejevic's quotation above, Marx's relational focus here meets the psychoanalytic interest of this paper; after all, if users are indeed caught up in an alienating, estranging and reifying relation with a corporate SNS, the foremost task is to describe in detail the characteristics of this relation.

In order to fully savour what the relational focus in Marx's early statements might mean for an inquiry into users' relations to a corporate online SNS it is worth taking a look at Rahel Jaeggi's (2005) social-philosophical approach to alienation. Summing her own take on the concept up in the formula of "a relation of unrelatedness", Jaeggi explains: "alienation does [...] not mean the absence of a relation, but is a relation itself-if only a deficient one" (Jaeggi 2005, 19, our translation). She chooses Marx's passage in the Economic and Philosophic Manuscripts (1844) as her point of departure. This description of alienation, she writes,

already contains both aspects, which according to my thesis are the main points of Marx's discussion of alienation. Firstly, what we find as being thought together here (i.e.

\footnotetext{
${ }^{1}$ Marx here uses the term "species being" which can roughly be defined as the anthropological potential of a human being in a given historical situation (see Marx 1844 [1956/2009], 32).
} 
in the field of tension between appropriation and alienness, S.K. and J.J.) are two problems: that of the 'loss of meaning', of impoverishment and 'meaninglessness of the world', and that of impotence and powerlessness vis-a-vis this world. Secondly, what shows in this central text of Marx's theory of alienation is the specific twist that Marx adds to the problem of the unrelatedness between world and human being: the scandal of alienation is that it is an alienation from what one has done and made oneself. It is our own activities and products, the social institutions and relations that we have created ourselves, which here become an alien power (Jaeggi 2005, 29-30, our translation).

Jaeggi's understanding of the concept is valuable to our approach as she translates Marx's various points into a subjective (but by no means subjectivist) state of being alienated - i.e. the vague and paradoxical feeling of being related to what one experiences as strange and the paralysing meaninglessness and powerlessness as the dominating feelings in this relationship. The particular value of this reading of Marx's early definition of alienation for the field of digital labour lies in the perspective it provides for thinking Andrejevic's observation of the return of one's own activities in disguised form further. Specifically, it allows us to ask how the returning of the users' activities impacts on these very users, their interactions with the social media platform, with each other, and their produce. In this respect, Jaeggi's translations of Marx's formulations into "the inability to identify meaningfully with what one does and with whom one does it with", as well as "the inability to exert control over what one does" (Jaeggi 2005, 30) become touchstones in and for our analysis of online alienation.

Thus equipped, let's take a look at the debate on digital labour and the place of alienation within it, before turning to our own exemplary readings of online alienation.

\section{Alienation in Digital Labour}

The field of digital labour studies has seen an immense rise in popularity; in the past years research has tackled the relationship between users and forms of unpaid or paid digital practices that produce exchange and use value (Terranova 2000; Kücklich 2005; Mosco and McKercher 2007; Burston, Dyer-Witheford and Hearn, 2010, Manzerolle 2010, Comor 2010, Dyer-Witheford 2010; Kang and McAllister 2011; Fuchs 2010, 2012a; Fuchs and Sevignani 2013; Scholz 2013). The argument that has been made by various scholars in the digital labour debate is that many forms of online practices do not appear to be labour but, in fact, contribute significantly to, say, the value of a website or online game. For a number of years, academic writing that does not specifically subscribe to the term "digital labour" but investigates "virtual work" from a critical perspective has also proliferated (e.g. Dyer-Whiteford 2001; Greenhill and Wilson 2006; Hermann 2009; Huws 2009). ${ }^{2}$

In order to provide a common basis upon which to build our argument, we will give a brief description of digital labour as it has been put forth-and defended plausibly - by Marxist oriented researchers, such as Christian Fuchs (e.g. 2012a). This position draws heavily on Dallas Smythe and his political-economic study on media audiences $(1977 ; 1981)$. Smythe argues that what is sold in commercial media is not so much programmes to audiences, but audiences to advertisers. The volte of Smythe's approach is that it is the audiences themselves who are turned into commodities. Advertisers pay television channels for air time in order to be granted access to these audiences. The bigger the audience of a specific programme, the more money a channel can charge for its exposure to other messages. Smythe therefore held that the reception activity of audiences constitutes a form of unpaid labour. If no one would do the labour of watching a TV programme, no company would want to have advertisement placed on it. Watching television thus marks the unequal exchange of a television programme for the audience's time and attention.

Smythe's model becomes particularly relevant when transferred to the Internet and applied to user-generated content (Fuchs 2012a) where the central task of value production is "out/crowdsourced" to the users. In order to emphasise this basic conflation of the spheres of consumption and production on corporate online platforms, Alvin Toffler's term of the

\footnotetext{
${ }^{2}$ We follow Fuchs's and Sevignani's $(2013,240)$ definition of the term "labour" in this paper.
} 
"prosumer" (1980) has been adapted to this context, signifying that the service's user produces goods (which the service owner then commodifies) not only while consuming the service offered but rather: by consuming this service. The products thus produced are "usergenerated data, personal data, social networks and transaction data about [users'] browsing behaviour and communication behaviour on corporate social media" (Fuchs 2012a, 708). Fuchs continues that "[c]orporate social media sell the users' data commodity to advertising clients at a price that is larger than the invested constant and variable capital," making it partly the users and partly the corporations' employees that "create the surplus value contained in this commodity. The difference is that the users are unpaid and therefore-in monetary terms-infinitely exploited" (Fuchs 2012a, 713).

In bold strokes, these are the outlines of the dynamics of digital labour from a political economic perspective. Whereas the dictum of infinite exploitation is, as Fuchs cautions, limited to the monetary dimension (2012a), the point of alienation is decisively more open to subjective interpretations. Returning thus to alienation, Fuchs and Sevignani (2013, 257-259) use the four dimensions of alienation that they found in Marx's Grundrisse (see above) in order to sound out its scope on Facebook, the biggest SNS online. The authors use broad, general categories, such as ownership, ideological coercion, instrumentalisation and commodification of data to outline the functional character of online alienation. Thus, users are alienated from themselves because they are coerced to use Facebook by way of peer pressure and a lack of viable alternatives (Fuchs and Sevignani 2013, 257); users are alienated from "the instruments of labour" because they do not own the communication platform itself and because their "brains, hands, mouths, ears and speech, the Internet and platforms" are instrumentalised "for advertising" (ibid, 258); moreover, users are alienated from the "objects of labour" on Facebook-which the authors identify as shared representations of experiences- "through a legally binding agreement" (ibid, 259) that makes it possible for the platform owners to use them for economic purposes; and finally users are alienated from the product of labour due to the peculiar divide between use-value and exchange-value of symbolic produce online: the "use-values that Facebook users create are at the same time commodities that Facebook offers for sale on a market" (ibid).

From our perspective, the problem with such a categorical treatment of alienation is that it merely claims its existence theoretically instead of describing it phenomenologically. Such description would have to take into consideration the relational dimensions of being alienated in the ways outlined above. Fortunately, Fuchs and Sevignani (2013) also provide a measure of such phenomenological description when they introduce their concept of the "inverse fetish character of the social media commodity" $(2013,261)$ and offer an exemplary articulation: "In the world of digital labour," the authors write,

\begin{abstract}
the fetish character of the commodity takes on an inverted form. We can speak of an inverse fetish character of the social media commodity. The commodity character of Facebook data is hidden behind the social use-value of Facebook, i.e. the social relations and functions enabled by platform use. The inverse fetish of Facebook is typically expressed in statements like 'Facebook does not exploit me because I benefit from it by connecting to other users'. The object status of users, i.e. the fact that they serve the profit interests of Facebook, is hidden behind the social networking enabled by Facebook (Fuchs and Sevignani 2013, 261).
\end{abstract}

In a more empirically directed study, Sebastian Sevignani (2013) elaborates along the lines suggested by the concept of "inverse fetishism" (Fuchs and Sevignani 2013, 261). Based on qualitative interviews with 30 students, he identifies "trade-off strategies between privacy needs and perceived user benefits" (Sevignani 2013,332) as potential sites for "prosumer alienation" to become articulated. However, the author abstains from presenting concrete online material, but rather offers summarising interpretations: "The only thing SNS users can do is to limit their information disclosure no matter if they are SNS literate or not" (ibid). It is at that point of the trade-off that Fuchs and Sevignani's ideal example-"Facebook does not exploit me because I benefit from it by connecting to other users"-might be true to a certain, negotiated extent. 
One more contribution needs mentioning before we turn to our depth-hermeneutic inquiry into exemplary cases of online alienation, specifically, that of Eran Fisher (2012). With his wish to highlight "the humanist aspects in Marx's critique of capitalism and distinguish it from his more structural and economic critique" $(2012,173)$, Fisher approximates a notion of alienation that is in line with Jaeggi's and our own (lack of control; lacking ability to relate). The aim of his study, specifically to "highlight the contradictions of capitalism from a humanist viewpoint" (ibid), coincides with the present approach as well. However, the main thesis that Fisher puts forth on this basis seems somewhat too neat. This thesis-the existence of an inverse-proportional relation between exploitation and alienation-is summed up in the title of his paper, "How Less Alienation Creates More Exploitation?" While we find the overall direction of this argument thought provoking, Fisher's simple equation of de-alienation with such suspiciously affirmative categories as "self-expression, authenticity, and relations with others" appears highly problematic. "[l]n order to be de-alienated," Fisher writes, "users must communicate and socialize: they must establish social networks, share information, talk to their friends and read their posts, follow and be followed. By so doing they also exacerbate their exploitation" (Fisher 2012, 179). This simple acceptance of user interaction as de-alienating seems remarkable-especially in the face of the many piercing observations of potentially alienating constellations and affordances on SNSs that Fisher offers otherwise. Amongst these observations are: Facebook's inherent bias towards communication $(2012,175)$, and specifically towards that of the mundane and the emotional (ibid, 177); the "position of forced reflexivity" that users are put into and the subsequent categorising and "rationalising of selfdisclosure" (ibid, 176), the registering and expressing of emotions "almost as they occur", as well as the construction of identity through a "web of 'Likes"' (ibid, 177). It seems to us as though Fisher discards these observations in an attempt to unambiguously side with the users while disregarding the other dimensions of alienation.

Let us briefly recapitulate our theoretical frame. Rahel Jaeggi's reading of Marx's early definition of alienation emphasises the failing act of identification and appropriation on part of the workers, as well as the concurring feelings of meaninglessness and powerlessness. It is this reading that guides our understanding of other researchers' approaches to the question of alienation in digital labour-approaches that are crystallised in concepts such as ideological coercion, instrumentalisation, inverse fetishism, etc.

\section{Scenes of Online Alienation}

Building a bridge to our approach to online alienation via Alfred Lorenzer's method of "scenic understanding" (1970, 139-141), let us take one more look at Rahel Jaeggi's remarks on alienation. When Jaeggi cautions other authors to be economical in their assessments of alienation by writing that, "a life form could be criticised as wrong without there existing the equivalent of a subjective perception of psychological strain" (ibid, 47), such subjective perception as the point of departure for her own narrative approach becomes clear. Depthhermeneutics shares this starting point. In the introduction of On the Foundation of a Materialist Theory of Socialisation (Zur Begründung einer materialistischen Sozialisationstheorie, 1972), one of the central documents of Alfred Lorenzer's project of a materialistpsychoanalytic social science, he writes:

It is the task of psychoanalysis [in social science and cultural studies; S.K.] to render more precise in content those terms that have been abstracted from the analysis of objective societal processes, as for example 'alienation.' This is done through a critical process that departs from the sensually experiencable suffering of the subjects. We have to put into question the 'real' genesis of concrete suffering in order to uncover in these places an ideological veiling of the subjective factor that only Freud began to tear open. ${ }^{3}$ (Lorenzer 1972, 15, our translation)

\footnotetext{
${ }^{3}$ German original: „Psychoanalyse hat die Aufgabe, die aus der Analyse objektiver gesellschaftlicher Prozesse abstrahierten Begriffe wie z.B. ,Entfremdung inhaltlich zu präzisieren in einem kritischen Verfahren, das von dem sinnlich-erfahrbaren Leiden der Subjekte ausgeht. Es gilt, konkretes Leiden in seiner ,wirklichen' Genese zu hin-
} 
Terms that were once won from concretely analysing societal processes, such as alienation, are to be brought in touch again with equivalent processes in an individual's given historical situation. Yet, these processes are not initially approached from the side of the social conditions, but, first of all, from that of the "sensually experiencable suffering of the subjects" (ibid).

In the following, we would like to present Lorenzer's theory and method by way of a demonstration, rather than explanation; in this way we hope to do justice to Lorenzer's materialist appreciation of a practical encounter with concrete socio-cultural practice (Lorenzer 1972, 9; Bereswill et al 2010), as well as contribute ideas and insights to the present understanding of online alienation. For this task, the question of how to identify and locate concrete articulations of alienation in everyday individual online practice becomes decisive. Therefore, a depth-hermeneutic inquiry into Facebook (to stay with the most common example), would have to depart from those realms of discourse and symbolic interaction where such concrete articulations become clearly perceivable-not only as subjective perceptions, but as perceptions relating to Facebook as the, or an Other in the interaction. What is thus at stake in a depth-hermeneutic inquiry is the relatedness and relation between a societal institution and the individuals interacting with this agency. Arguably, this is the case on the Facebook Site Governance page that the platform introduced in 2009. ${ }^{4}$ Here users are invited to discuss, and in some cases vote on changes in the programming and user policies (Fuchs and Sevignani 2013, 258). Entering into a dialogue with this page, depth hermeneutics applies a mode of "scenic understanding" (Lorenzer 1970) in which the researcher is to use her/his own subjectivity-her/his own experiences and culturally formed expectations-in order to detect within him/herself the irritations arising from her/his relating to the text.

Under standard methodological conditions, then, the task of a depth-hermeneutic inquiry into Facebook would be to detect and gather the irritations resulting from the researcher(s)'s reading of materials such as the comments on the Site Governance website. The selection made in this way is then ordered and systematised not according to cognitive categories, but relational and affective ones, specifically, the similarities in the forms that the researcher's irritations have taken. Lorenzer here writes of "experiences of evidence" that are tied to interaction patterns: "It is the interaction patterns that allow us to recognize the most diverse experiences as variations of one and the same scenic arrangement" (Lorenzer 1970, 144, our translation). The collection of material is continued in this way until the identification of typical interactional patterns has become saturated.

Thus embarking on the methodological task of "scenic understanding"-a task which we have severely simplified for our summary here-we hope that the reader can see that this task is usually much less specific, as well as more open(-ended), than that of the present article, which is to detect, identify and describe alienation on SNSs. Simply put: while in a fully fledged depth-hermeneutic approach to Facebook identifying interaction patterns as alienated/alienating would be one possible outcome amongst others, we will direct our attention straightforwardly to those aspects in our material that can be linked to the conception of alienation that we put together from the pertaining literature above.

The material that we have chosen for our demonstration is taken from the comment section to the post "Thanks for your feedback" by Facebook's Chief Privacy Officer, Erin Egan, posted on Facebook's Site Governance website on 15 November, 2013. Egan's post seeks to clarify the "changes we proposed recently to our Data Use Policy and Statement of Rights and Responsibilities" (Egan 2013, no page numbers) and obviously tries to deflect accusations put forth by commentators throughout the posts to the page: "We want you to know that nothing about this update has changed our advertising policies and practices. We heard this question a lot so we want to be clear. The goal of the update was to clarify language, not to change policies or practices" (Egan 2013, no page numbers, emphasis in original). From a thread containing 529 comments we chose a mere six for further analysis. From such a rela-

terfragen, um an diesen Stellen eine ideologische Verschleierung des subjektiven Faktors, den erst Freud aufzureißen begann, zu durchschauen." (Lorenzer 1972, 15)

${ }^{4}$ https://www.facebook.com/fbsitegovernance/app_4949752878 (accessed on 9 June, 2014). 
tively small number it is not possible to identify consistent patterns of interaction for the site. What we can and want to do nevertheless is to identify certain tendencies that might point us towards more consistent attitudes held on the site.

A first such tendency can be accessed via a set of comments that compare Facebook to Google, the other Internet monopolist. Thus writes a user in the thread under Egan's remarks: "At least Facebook tries to explain what is going on, UNLIKE GOOGLE" (15/11/2013), to which another user seems to add loosely: "At least it doesn't deceive like Google does" (15/11/2013). At the surface level, what are traded here are modes and quantities of an acute dissatisfaction on part of the users with the ways they are treated by social media services. More important, however, are the concrete forms that the articulations of this dissatisfaction take. In order to inquire into this, we would like to shift gears now and present some of our free associations in view of the material. This is a further methodological step of depth hermeneutics; Lorenzer suggests for a group of researchers to come together and freely associate to the collected material in order to refer these associations, as well as the group dynamics arising from the discussion-conflicts between researchers, shared emotional states, images, etc.-back to the material, making them fertile for the material's interpretation; this being a methodological idea that Lorenzer borrowed from psychoanalytic group supervision (Lorenzer 1986, 43; Balint, 1964).

\subsection{A Pleasurable Sense of Importance}

For us the irritations emanating from the two comments above are related to the theatrical posture carried by word choices and choices of phrasing, such as "at least" or the high-case "UNLIKE GOOGLE". What the two posts triggered in us were notions of juvenile intrigue and high school drama of the kind that one frequently encounters in US-American television series catering for teenagers. Facebook and Google appear to be cast in the roles of conniving, two-timing and coolly plotting lovers whose actions command their partners' attention even in their absence.

To be sure, this notion of juvenile drama is by no means intended as a characterisation of the commentators themselves; we do not have any more information about them than what can be gathered from the comments to Facebook's Site Governance page themselves. By contrast, our point is exactly to treat these comments as characteristic of the piece of symbolic interaction they are part of. Putting forth the notion of juvenile drama, then, is meant as a suggestion of a relevant character trait of the relation between Facebook and its users. Granting our two comments some paradigmatic force, what this notion says about this relation is first of all that there is a high expectation of being fooled on part of these users and agreement amongst them about the platform's reputation: "one just cannot trust it". Clearly, the two comments show themselves to be hurt and disappointed. At the same time, however, there is an attempt to find solace in this by emphasising the residual good that can be found in the partner: "at least Facebook tries to explain" (although it does not succeed, one could add); "at least it doesn't deceive" (although sometimes it comes close). The comparison of degrees of immorality renders the less immoral part tolerable and legitimate.

Now, we are aware of how eccentric such formulations as the above ones will appear within a conventional academic paper; however, we find it important to demonstrate some of the free-associative material in order to work out the core point that we want to make about the two comments' meaning for the relation between Facebook and its users. Specifically, we find that the lack and the deficiencies which the comments point to are not simply and exclusively suffered as deficiencies but also enjoyed and celebrated to a degree for their value as scandals in which one is personally involved. It seems to us that the indignation that is being enacted by those comments is experienced as partly pleasurable because it endows both, the ones articulating this indignation and those taken into confidence (the authors of this present article, for example), not only with a sense of righteousness but, not least, with a sense of importance. Venting and calling forth feelings of indignation and having them acknowledged and objectified is thus suffused with narcissistic pleasure. This seems to us to show parallels to a process of coming off age and joining the world of grown-ups, where personal 
relations have weight and importance and one's actions real-life consequences. "Is this really happening to me? Is it really I who is part of this?" At the same time, this sense of maturity and importance emanating from the comments appears to be performed in a playful and somewhat inconsequential manner. Therefore, we feel that the kind of "deception" that the two comments deal with can and will be put aside if the deceiver only shows a quantity of remorse towards his/her partner(s).

In compressed form, what we can thus identify in the pose of the two commentsLorenzer would call them "scenes" $(1986,60-62)$-is a pleasurable, narcissistic sense of personal importance derived through the enactment of indignation over an experience of being deceived-an experience of impotence. Turned the other way around, what this constellation could mean for the users' relation with the Facebook platform is that there is a common experience of powerlessness, of being disappointed and hurt, that users render tolerable, even pleasurable, through a mutually affirming performance of indignation that serves to take the consequence-that of impotence, immorality, deception etc.-out of the perceived reality of the relation.

Referring these observations back to Jaeggi's definition of alienation, they allow us a glimpse of what shape the "relation of unrelatedness" (Jaeggi 2005, 19) might take on SNSs. In our two scenes a notion of meaninglessness announces itself in the exaggerated and clichéd theatricality in which the comments fashion their indignation: "at least", "UNLIKE GOOGLE". However, the re-enactment of the relationship seems well rehearsed and devoid of spontaneity and it might just as well be such routine which protects the relation from the insight into its meaninglessness. This form of theatricality also takes the edge off one's powerlessness in the face of the platform's actions. It distracts and glosses over the consequences of one's relation with the SNS, which would otherwise become fully perceivable and experiencable.

\title{
5.2. Staging a Breakdown in Relations
}

Giving our above findings of a notion of self-importance and its affirmative effects more relief, we can refer to another, very common type of post which is characterised by the staging of a breakdown in the relation with the SNS that is attacked:

\begin{abstract}
If my posts are glitched anymore..I mean they are actually taken away from me..I will file.a lawsuit against Facebook..my son is a former Atty General..and he is fantastic prosecutor..I WILL FILE CHARGES WITH THE FED. TRADE COMM...I WILL HAVE THEM MONITOR MY POSTS AS I TYPE THEM..AND SEE FOR THEMSELVES..SICK OF YOUR LIBERAL CRAP..ARE YOU EVEN AMERICAN?????????????/ (24/05/2014)
\end{abstract}

Arguably, what one can identify here is an insight that realises in relational form what Fuchs and Sevignani $(2013,257)$ list as one of the aspects of alienation: "alienation from the objects/material of production" (ibid). After all, the user literally feels that he has been robbed. The persecuted and threatening feel of the post reaches far beyond its reference to consumer rights ("the Fed. Trade Comm.") that are seen as being attacked by Facebook as a corporation. In its attempt at enlisting us (the authors of this paper) as supporters of its accusations and denunciations, by seeking to convince us of its strength and authority ("my son is a former Atty General"), and by trusting us to share in its moral high ground (anti-liberal American) as well as its rage ("crap"), it achieved the exact opposite. Not only did the cultural differences between us (central European, left-leaning) and this post make empathy hard to come by; moreover, its accusations we felt to be poorly informed-a lack of insight into how Facebook works-its assurance of agency seemed to us a sure sign of powerlessness, its rage an unacceptable lack of control and composure, a demonstration of a deep, tormenting melancholia that we did not want to have a part in.

Whereas in the first set of posts, discussed above, what we found is a show of indignation that is half-serious and inconsequential and, in this way, amounted for us to an enjoyable avoidance of the insight into one's own powerlessness vis-à-vis the SNS, this post here 
brings its helplessness to the fore exactly in its attempt at acting up (and out) against the threat of meaninglessness and powerlessness that has befallen it.

Another example containing a very similar interactional pattern we found in a complaint by a user about being harassed by one or more other users-a complaint, which once again slides quickly into "ALL CAPS" mode. The post climaxes with "I MUST ASSUME THAT FACEBOOK HAS ENABLED THEM TO DO THIS, OTHERWISE_ HOW IS IT POSSIBLE!" $(22 / 05 / 2014$, extract). What we find here again is screaming, outrage as a counterpart to the comparatively mild, (self)-ironic form of indignation above. Once more this outrage brings the mode of playing along to a halt which is maintained in the other set of posts. And once more powerlessness is articulated in the empty threat of contacting "the federal authorities if this sort of HARASSMENT of me continues". Finally, in a parallel to the displacement of aggression towards liberalism ("liberal crap") in the former post, we again find rage being channelled towards a conspiracy-theoretical object par excellence: "the Fasclst-in-Chief__t that piece of shit DESPOT OBAMA." (22/05/2014, extract).

Are these two last posts examples of a specific kind of alienated situation? The strong projective tendencies and conspiracy-theoretical fantasies at least point to a condition in which acute feelings of powerlessness and meaninglessness in one's own innermost relations are fought off with considerably desperate means. Despite the posts' strong affinities to some of the variables that Fuchs and Sevignani (2013) deduce from Marx's four dimensions in Grundrisse (i.e. alienation from the instruments; alienation from the objects), it is not clear at all whether this enraging feeling of disorientation which is enacted here, is related to the structuration of labour on Facebook itself or rather to an inability to use the network in the way intended by its owners. This latter case would be one of lacking knowledge, rather than one of a deficiency in the relation to oneself and others due to one's realisation of the specific relations of production on the SNS.

\subsection{A Reified Sense of Entitlement}

There is one more set of posts which we would like to discuss here and with which we would like to return to the sense of importance that struck us in the first set of posts that we presented. In the following posts we find that this sense of importance is frequently attached to another such sense, namely one of entitlement and worth. User "Steve Smith", for example, shares a stylishly laid out message by a user or user group named "Social Fixer". This message provides a list of demands and instructions addressed to Facebook: "Dear facebook," it reads, "The Newsfeed is getting worse! Here is what I want", followed by instructions that are reasonable in content-e.g. "Posts in the order they were posted"-yet, at the same time, curiously impatient and familiar in form, e.g. "[I want] All my friends' posts. Not just what you think I will like" (08/12/2013, our emphasis). In contrast to the second set of posts (staging a breakdown) there is no trace of acting out here; rather, one can draw comparisons to the initially discussed ones whose playful form of indignation also produced notions of proximity and familiarity. Probably the clearest example of the relational aspect that we think is behind this intimate form of demanding things and the sense of entitlement that drives it appears in a comment that was posted a number of times in the threat that we looked at, with the text obviously having been copied, pasted and thus identified with by various users on the page, thus approaching the status of a meme.

Do not collect my data. Do not use my data without my specific hand written permission for each item. Do not release my personal information whether written of me by someone else or by me, past, present and future without my hand written permission or a court order. If you do use my personal and private information I shall be notified immediately and paid for it whether it was used previously or will be used in the future. I DO NOT AUTHORIZE the use or collection of my personal information I have given to or shared with Facebook, past or present, which includes but is not limited to my messages, notifications, friends, texts, photos, images, comments or any other content contained in or on my profile or timeline including information I have shared on anybody's Facebook account whether current or deleted for any reason or purpose other than my own personal use 
and purpose of my Facebook account. I hereby declare that my copyright is attached to everything I have done and will ever do with my Facebook account and my handwritten consent is required at all times with no exception for any purpose other than my own regarding the information contained in it or on it. (e.g. 05/04/2014, extract)

Needless to say, commentators did in fact authorize the use of their personal information when they ticked off the terms and conditions agreement as part of the Facebook membership procedure. Therefore, the post's juridical tone-"I hereby declare"-is not endowed with the authority that it requires. The incongruence between the mode of speech and the actual position of the one speaking produces a somewhat tragicomic effect. Yet, what is important to us in this post is that the distribution of being deserving on part of the comment/commentator and an acute sense of obligation located on part of the other, i.e. Facebook, speaks of the same injury that we found present but glossed over in the posts above. The obsessive desire of being met in one's demands down to the most minuscule detail seems to be a reaction to having been disappointed, utterly and beyond repair, and can thus be seen as a continuation of the indignation performed in the first set of comments. In its repetitive phrasing of "do not" and its strong investment in the "handwritten", the post takes on notions of what early psychoanalytic theory called hysteria, with the idea of the forbidden, catastrophic touch-"I have been soiled"-forming the implicit counterpart of the fetishistic idea of the "handwritten"-the touch of genius. In this way, then, this post seems to conjure up the figure of a disappointed, deceived lover who cannot bring him/herself to leave the deceiver; instead s/he continues the process of hollowing out the relationship by nagging, ranting, and dishing out increasingly harsher rules of conduct, none of which can be expected to be truly followed or to truly change the deceiver's morals, let alone mend the relationship.

Also this last association is meant as an experimental insight into the relation between Facebook and its users and sheds light on the ways in which a lacking ability to identify with one's actions on the SNS and an experience of powerlessness are articulated in it. In this last case, the relation is articulated in an immensely bloated self-image that seems to mistakenly use Facebook's interest in the personally trivial and mundane (Fisher 2012, 177) for the bolstering of personal importance and exceptionality.

\subsection{Inverse Fetishism Revisited}

It is with this relational image in mind that we can return to Fuchs and Sevignani's concept of "inverse fetishism" $(2013,261)$. As stated previously, this concept argues that users deny the reifying aspects in their relationship with Facebook by emphasising the social gratifications they receive from using the service. What our exemplary findings so far brought to the fore in this respect is first of all the aspect of denial, i.e. that the threatening insight of being exploited, coerced and alienated has to be fended off on a mental plane. However, in comparison to Fuchs and Sevignani's example of "Facebook does not exploit me, because I benefit from it by connecting to other users", people in our cases addressed the forlornness of their relation with Facebook full on; at the same time, however, they seemed to use this very performance of indignation to (unconsciously) defend themselves against this knowledge. This means that, in our examples, what was defended against was not so much the knowledge of the deceiving, exploiting nature of Facebook itself, but of the consequences for the users arising from their partnership with Facebook. "Facebook exploits me, but that's not so bad as long as I can benefit from it by connecting to other users."

John Steiner's concept of "turning a blind eye" (1986) seems to offer an adequate umbrella for the various ways of defending against knowledge which Fuchs and Sevignani as well as our own experimental reading of posts has brought forth. Steiner refers to this mechanism as turning a blind eye because, as he writes, "I think this conveys the right degree of ambiguity as to how conscious or unconscious the knowledge is. [...] [W] are vaguely aware that we chose not to look at the facts without being conscious of what it is we are evading" (Steiner 1986, 161). Likewise, when Sebastian Sevignani writes that, "users are kind of aware that people who own and control the SNS are appropriating societally-produced surplus" 
(2013, 331, our emphasis), the phrase "kind of" seems to us to point to the very ambiguity that Steiner observes.

Taking the theme of "inverse fetishism" one step further, we would like to suggest that the commodity form does not simply remain "hidden behind the social use-value of Facebook", as Fuchs and Sevignani argue $(2013,261)$. Rather, it becomes identified with and enacted in the users' interactions with the SNS. Vaguely knowing how dubious their relation with Facebook is, the users' exacting demands and instructions, which we detected in our third set of posts, can be read as attempts at selling themselves as dearly as possible to the platform owners: "Do this, not that"; "Don't give me just what you think I like"; "Don't touch anything without my handwritten permission" etc. It is against this interaction pattern that the notion of the diva is evoked: just as a diva's mannerisms can be interpreted as acting up against a culture-industrial complex, which, paradoxically, is fed and reaffirmed by these actions, so can the exacting demands put forth in the comments we analysed be seen as means for the commentators to adapt to the corporate conditions of socialising on the platform and make themselves at home in an alienating, objectifying relation. "Well, if you want to instrumentalise me," these comments seem to tell Facebook, "then at least treat me as a precious instrument and maintain me well!"

\subsection{Trade-Off Strategies and Narcissism in User-User Relations}

Against the above extension of the concept of inverse fetishism we can also gain a new perspective on the trade-off strategies that Sevignani (2013) identifies as sites of alienation. From his interviews with users, Sevignani learns that the only viable strategy for users to strike a balance between privacy needs and privacy threats is "to limit their information disclosure" (Sevignani 2013, 332). Building on this, from what we found in our cases of users directly addressing Facebook as an imagined/imaginary other, we are rather pessimistic as to the consequences of such trade-off strategies for user-user relations, since the probability seems high that a user's sense of her/his commodification is also being worked into her/his interactions with other users. In this respect, a certain degree of narcissism, which users of SNSs are so often accused of falling prey to in popular journalism, seems system-inherent. Also such narcissism must be understood first and foremost as "a defence produced in response to misrecognition", as Aaron Balick explains from a relational psychoanalytic perspective $(2014,81)$. According to this perspective, then, the narcissist invests in a reified image of her/himself that is not entirely of her/his own making, but a coproduction between the platform and her/him, which works according to our description of instrumentalisation and self-reification above. Part of the trade-off thus seems to be a continuous, automated inspection of oneself along the lines of one's own "preciousness", not only with respect to one's Facebook friends, but also against the vague intuition that one is feeding one's own objectification as well as the return of one's data in disguise (Andrejevic 2011, 2014).

\section{Conclusion}

It was the task of this article to shed further light upon the concept of alienation and how it is experienced, as well as articulated in relational form online. For this purpose we made use of Marx's early formulations on alienation in the Economic and Philosophical Manuscripts of 1844 and Rahel Jaeggi's (2005) reading of the former. With Alfred Lorenzer's method of scenic understanding $(1970 ; 1986)$ we approached an exemplary selection of user posts to Facebook's Site Governance Page. Let us pull together the various threads of our article's argument by briefly reviewing our findings against the literature we used.

While Fuchs and Sevignani (2013) observe apropos their concept of "inverse fetishism" $(2013,261)$ that the object status of users is hidden behind the use value, our experimental, exemplary findings suggest, firstly, what form this latent objectification takes, secondly, what effects it might have on user-platform, as well as user-user relations. Thirdly, and consequently, our findings suggest that this objectification does make itself felt in these relations after all. It is these point that will occupy us in the following passages. 
As might be an expected bias of posts to the Site Governance Page, we found them to be astonishingly aware of them being instrumentalised. Contrary to the ideal statement of "Facebook does not exploit me, because I profit from it by connecting to other users" (Fuchs and Sevignani 2013,261 ), the postures taken in the posts we observed rather amounted to "Facebook does in fact exploit me, but that's not so bad because I profit from it by connecting to other users." Moreover, in a surprising realisation of Marx's early dictum in the Economic and Philosophical Manuscripts that the "estrangement of man [...] is realized and expressed only in the relationship in which a man stands to other men" (Marx, 1844 [1956/2009], 32) these posts seem to realise their estrangement by establishing a quasi-personal relation to Facebook. In the user experience, this notion of Facebook as a palpable Other seems to arise through what Andrejevic (2011) describes as the interchanging relation of users feeding data to the SNS and the SNS feeding these data back to the users in disguised form (through advertising, friend suggestions, selection of posts in the newsfeed, etc). It is in such moments, in which users obtain a glimpse of the SNS's "latent desires" as well as their part in them- "...] what you think I will like" (Social Fixer 2013) - that the impression of a certain character type arises, a type that the posts we looked at judged to be a chronically unfaithful, conniving lover- "one just cannot trust her/him".

However, despite the deep running mistrust towards Facebook which the posts demonstrate, we thought to detect in this very demonstration a missing willingness and/or ability to put an end to the relation. The indignation expressed in the posts appeared to us to be strangely clichéd and theatrical-a theatricality that in turn suggested to us the opposite of acting upon a vivid insight. Specifically, the subjects speaking through these posts seemed to derive a pleasurable sense of importance from being instrumentalised which seemed to help users "turn a blind eye" (Steiner 1986) and gloss over the consequences that their instrumentalisation has for them. This aspect of our findings also sheds new light on the dynamics of the concept of "ideological coercion" (e.g. Fuchs 2012, 732), specifically, that the repeated, mutual confirmation amongst users of being victims in the same intrigue takes the edge off the personal sense of powerlessness that the betrayal might otherwise have. In the cases we looked at it is thus the very articulation of indignation that serves as a safety valve and makes the continuation of the relation possible, if not pleasurable. "Oh, you know, it's Facebook-What can you do?" In this relation-affirming staging of indignation we therefore find a moment of alienation from oneself and from others in that the removal of consequence from one's relation with Facebook goes hand in hand with the removal of consequence from one's own symbolic interaction.

In this way, the relation with the deceiving partner is continued on the basis of a fundamental injury that has been derealised. Symptomatically, this injury shows in the increasingly impatient, at times literally hysterical demands with which the deceived unconsciously seeks to take revenge on, as well as control over, the partner and force upon him/her a compromised display of appreciation. This symptomatic finding seems to go most clearly against Fuchs and Sevignani's otherwise immensely fruitful concept of "inverse fetishism" (2013, 261): having reached a certain level of frustration with Facebook as a partner, posts begin to display signs of a regressive, destructive and most importantly: self-destructive reification and instrumentalisation of the self. "If I am an instrument for you, then at least treat me like a prescious instrument!" It is in this protesting act of self-reification that Rahel Jaeggi's reading of Marx's definition of alienation can best be unfolded. When several users copy, paste and post the same comment that displays a striking investment in the "handwritten" we can detect in their misconception of the value which they thus attribute to their symbolic produce that which Jaeggi calls "the inability to identify meaningfully with what one does and with whom one does it with" (Jaeggi 2005, 30). By contrast, the hysterical notions of the forbidden touch-"do not [...]"-in the same post appear clearly related to what Jaeggi calls "the inability to exert control over what one does" (ibid). Both dynamics are related and tied to one another and have their roots in the conditions of production on the SNS.

Extrapolating our findings, we scrutinised the thesis of "inverse fetishism" further, questioning in how far objectification would in fact remain hidden in user-user relations in the face of the symptoms that some of the posts to the Site Governance Page displayed. Drawing on 
the relational psychoanalytic conception of narcissism as a "defence produced in response to misrecognition" (Balick 2014, 81), we asked whether platform-driven objectification and instrumentalisation shows in user-user relations in the form of such narcissism. According to the definition presented here, narcissism can no longer be seen as a creation of which either the user or the SNS alone is responsible. Much rather, narcissism has to be understood as a co-creation between the users, the SNS, as well as the socio-cultural context within which a given user responds to the SNS's capitalist agenda with acts of self-reification-acts which again will have been culturally, as well as biographically rehearsed (ibid, 79). In order to say more about what Stephen M. Johnson calls the "narcissistic style" (1987) and its potential for online alienation, further studies will be necessary. These studies will have to take into consideration not only the relations of production on online SNS, but, as Aaron Balick cautions, both the wider "culture and family constellations" $(2014,79)$.

Rounding off the review of our findings, we see that it was only in the most extreme articulations of frustrations with the SNS-articulations that nevertheless can be seen as typical topoi in online discourse - that the state of alienation described above (a state which in all other posts observed was maintained in the continual hollowing out of the relationship) could be seen to break down. Even though we are unsure in these cases as to what degree we can relate the breakdown to the posts' relation to the SNS directly, the disorientation as well as the strong projective responses tied to this disorientation appear characteristic of the release of psychic energy that was formerly bound by a (self-)destructive relationship. As different as these incidents of acting out might seem from the milder forms of indignation experienced in the other posts, they can still be placed on the same continuum. While the posts that remained attached to the SNS turned this SNS into a quasi-person in order to enter into what psychoanalysis calls a "family romance", the posts staging a breakdown in relations had to rely on a concrete counterpart. In the open confrontation with their powerlessness vis-a-vis the network, these latter posts set up characteristic conspiracy-theoretical objects for their projections, for example "the Fasclst-in-Chief_that piece of shit DESPOT OBAMA" (22/05/2014, extract).

In an article from the late 1990s, the German social psychologist Gerhard Vinnai analysed the affectively charged "family romances" that people in Germany created in relation to Princess Diana after her tragic death in a car accident in Paris in 1997. People fantasised themselves to be on intimate terms with the "people's princess", reporting her to be like a sister, a mother, daughter, best friend, etc. Vinnai interprets these romantic fantasies as compromise constructions: in a socio-cultural, socio-economic set up in which people can no longer see through the complexity of the resulting relations, these romances help them make sense of their own place within them-albeit in a precariously regressive and reductive way.

\begin{abstract}
The tendency of falling back behind once secured stages of social emancipation has its counterpart in a dubious urge for the familiar. That people should turn into social beings, that they should become culturally and politically enabled, demands the loosening of childish ties to one's family origins. It demands that one leave behind the limited orientation towards the family in favour of becoming interested in more complex social interrelations. The urge to escape from burdening social realities facilitates the regression to familiar experiences of relations that are then transferred to social structures for which they are not adequate (Vinnai 1998, no page numbers, our translation).
\end{abstract}

We feel that this theme of family romantic relations standing in for and covering up a much harsher political-economic reality is highly applicable to the users' relations to Facebook and has been an undercurrent in nearly all our observations on online alienation. It is in light of these family romances that we deem Fisher's (2012) neat equation of more-exploitation-lessalienation to be in need of revision. Arguably, social networking online might help a large number of people strengthen their social ties. However, while the generation of exchange value from these networking activities remains mostly hidden to the users, it remains all but ineffective. 


\section{References}

Andrejevic, Mark. 2014. Alienation's Returns. In Fuchs, Christian and Sandoval, Marisol, eds. Critique, Social Media and the Information Society, 179-190. New York: Routledge.

Andrejevic, Mark. 2011. Surveillance and Alienation in the Online Economy. Surveillance \& Society 8 (3): 278-287.

Balick, Aaron. 2013. The Psychodynamics of Social Networking: Connected-up Instantaneous Culture and the Self. London: Karnac.

Balint, Michael. 1964. The Doctor, his Patient and the IIIness. London: Pitman Medical Publishing.

Bereswill, Mechthild, Christine Morgenroth and Peter Redman. 2010. Alfred Lorenzer and the Depth Hermeneutic Method. Psychoanalysis, Culture and Society, 15 (3): 221-250.

Burston, Jonathan, Nick Dyer-Witheford and Alison Hearn, eds. 2010. Digital Labour: Workers, Authors, Citizens. Ephemera: Theory \& Politics in Organization 10 (3): 214-221.

Comor, Edward. 2010. Digital Prosumption and Alienation. Ephemera: Theory \& Politics in Organiza tion 10 (3): 439-454.

Comor, Edward. 2011. Contextualizing and Critiquing the Fantastic Prosumer: Power, Alienation and Hegemony. Critical Sociology 37(3): 309-327.

Dyer-Whiteford, Nick. 2001. Empire, Immaterial Labor, the New Combinations, and the Global Worker. Rethinking Marxism: A Journal of Economics, Culture \& Society 13 (3): 70-80.

Dyer-Witheford, Nick. 2010. Digital Labour, Species-becoming and the Global Worker. Ephemera: Theory \& Politics in Organization 10 (3):484-503.

Elster, Jon. 1986. An Introduction to Karl Marx. Cambridge: Cambridge University Press.

Fisher, Eran. 2012. How Less Alienation Creates More Exploitation? Audience Labour on Social Net work Sites. tripleC_Journal for a Global Sustainable Information Society 10 (2): 171-183.

Fromm, Erich. 1961. Marx's Concept of Man. New York: Frederick Ungar.

Fromm, Erich.1965. The Sane Society. New York: Rinehart and Winston.

Fuchs, Christian and Sebastian Sevignani. 2013. What is Digital Labour? What is Digital Work? What's their Difference? And why do these Questions Matter for Understanding Social Media? tripleC_-Journal for a Global Sustainable Information Society 11 (2): 237-293.

Fuchs, Christian. 2012a. Dallas Smythe Today-The Audience Commodity, the Digital Labour Debate, Marxist Political Economy and Critical Theory. Prolegomena to a Digital Labour Theory of Value. tripleC_-Journal for a Global Sustainable Information Society 10 (2): 692-740.

Fuchs, Christian. 2011. An Alternative View of Privacy on Facebook. Information (2): 140-165.

Fuchs, Christian. 2010. Labour in Informational Capitalism. The Information Society 26 (3): 176-196.

Garnham, Nicholas. 1986. Contribution to a Political Economy of Mass-communication. In

Media, Culture \& Society: A Critical Reader, edited by Richard Collins, et al., 9-32. London: Sage.

Giritli Nygren, Katarina and Gidlund, Katarina L. 2012. The Pastoral Power of Technology. Rethinking Alienation in Digital Culture. tripleC_Journal for a Global Sustainable Information Society 10 (2): 509-517.

Greenhill, Anita and Melanie Wilson. 2006. Haven or Hell? Telework, Flexibility and Family in the ESociety: a Marxist Analysis. European Journal of Information Systems 15: 379-388.

Hermann, Christoph. 2009. Value and Knowledge: Insights from Marxist Value Theory for the Trans formation of Work in the Digital Economy. Rethinking Marxism: A Journal of Economics, Culture \& Society 21 (2): $275-289$.

Horkheimer, Max and Theodor W. Adorno. 1972. Dialectic of Enlightenment, New York: Seabury Press.

Huws, Ursula. 2009. The Making of a Cybertariat? Virtual Work in a Real World. Socialist Register 37: $1-23$.

Jaeggi, Rahel. 2005. Entfremdung. Zur Rekonstruktion eines sozialphilosophischen Begriffs. Frank furt/M.: Campus Verlag.

Kang, Hyunjin and Matthew P. McAllister. 2011. Selling You and Your Clicks. Examining the Audience Commodification of Google. tripleC - Journal for a Global Sustainable Information Society 9 (2): 141-153.

Kücklich, Julian. 2005. Precarious Playbour: Modders and the Digital Games Industry. Fibreculture Journal 5. http://five.fibreculturejournal.org/fcj-025-precarious-playbour-modders-and-the-digitalgames-industryl (accessed on December 02, 2013).

Lorenzer, Alfred. 1972. Zur Begründung einer materialistischen Sozialisationstheorie. Frankfurt/M.: Suhrkamp.

Lorenzer, Alfred. 1970. Sprachzerstörung und Rekonstruktion. Vorarbeiten zu einer Metatheorie der 
Psychoanalyse. Frankfurt/M: Suhrkamp, 1995.Lorenzer, Alfred. 1986. Tiefenhermeneutische Kulturanalyse. In Kultur Analysen:Psychoanalytische Studien zur Kultur, edited by Alfred Lorenzer, 11-98. Frankfurt/M.: Fischer.

Lorenzer, Alfred and Peter Orban. 1978 (1988 edition). Transitional Objects and Phenomena: Socialisation and Symbolisation. In Between Reality and Fantasy. Winnicott's Concepts of Transitional Objects and Phenomena, edited by Simon A. Grolnick, Leonard Barkin and Werner Muensterberger, 1-34. Northvale: Jason Aronson.

Manzerolle, Vincent. 2010. Mobilizing the Audience Commodity. Digital Labour in a Wireless World. Ephemera: Theory \& Politics in Organization 10 (3): 455-469.

Marcuse, Herbert. 1966. Eros and Civilization. Boston: Beacon Press.

Marx, Karl. 1959. Economic and Philosophic Manuscripts of 1844. New York: Prometheus Books. Proofed and corrected version by Matthew Carmody published online in 2009. https://www.marxists.org/archive/marx/works/download/pdf/Economic-Philosophic-Manuscripts1844.pdf.

Marx, Karl. 1873 [1857-61]. Outlines of the Critique of Political Economy [Grundrisse]. London: Penguin. $\quad$ Published online 1997. http://www.marxists.org/archive/marx/works/download/Marx_Grundrisse.pdf.

Mosco, Vincent and Catherine McKercher, eds. 2007. Knowledge Workers in the Information Society. Lanham, MD: Lexington Books.

Musto, Marcello. 2010. Revisiting Marx's Concept of Alienation. Socialism and Democracy 24 (3): 79 101.

Scholz, Trebor, ed. 2013. Digital Labor. The Internet as Playground and Factory. London: Routledge.

Sevignani, Sebastian. 2013. Facebook vs. Diaspora: A Critical Study. In Unlike Us Reader. Social Media Monopolies and Their Alternatives, edited by Geert Lovink and Miriam Rasch, 323-337. Amsterdam: Institute of Network Cultures.

Smythe, Dallas W. 1981. Dependency Road. Norwood, NJ: Ablex.

Terranova, Tiziana. 2000. Free Labor. Producing Culture for the Digital Economy. Social Text 18 (2): 33-58.

Toffler, Alvin. 1980. The Third Wave. New York: Bentam.

Vinnai, Gerhard. 1998. Das Diana Syndrom. Über eine Unfähigkeit zu Trauern. Widersprüche: Zeitschrift für sozialistische Politik im Bildungs-, Gesundheits- und Sozialbereich 68. Published online June 1998. http://www.vinnai.de/diana_syndrom.html.

\section{About the Authors}

\section{Steffen Krüger}

is postdoctoral researcher at the Department of Media and Communication, University of Oslo, Norway. He is contributing editor of the journal American Imago. His PhD thesis about the psychoanalyst and-for the time World War II-propaganda researcher Ernst Kris was published as Das Unbehagen in der Karikatur (Fink, 2011). In his current research project, Online Interaction Forms, financed by the Norwegian Research Council (NFR), he analyses forms of digital media discourse from a psychosocial, and specifically, depth-hermeneutic perspective.

\section{Jacob Johanssen}

is a PhD student in Psychosocial Studies at the University of East London (UK). His research interests include digital culture, critical theory, psychoanalysis and media as well as audience research. Publications include "Cyborg Subjects: Discourses on Digital Culture" (edited with Bonni Rambatan, 2013). His PhD thesis explores a psychoanalytic conception of the subject that is both theoretical and epistemological. The research involves interviews with viewers of "Embarrassing Bodies" and explores their investments, fantasies, and viewing practices. 